\section{Arquitectura; metafísica, prospectiva tecnològica o preocupació social?}

\author{
Arnau Puig
}
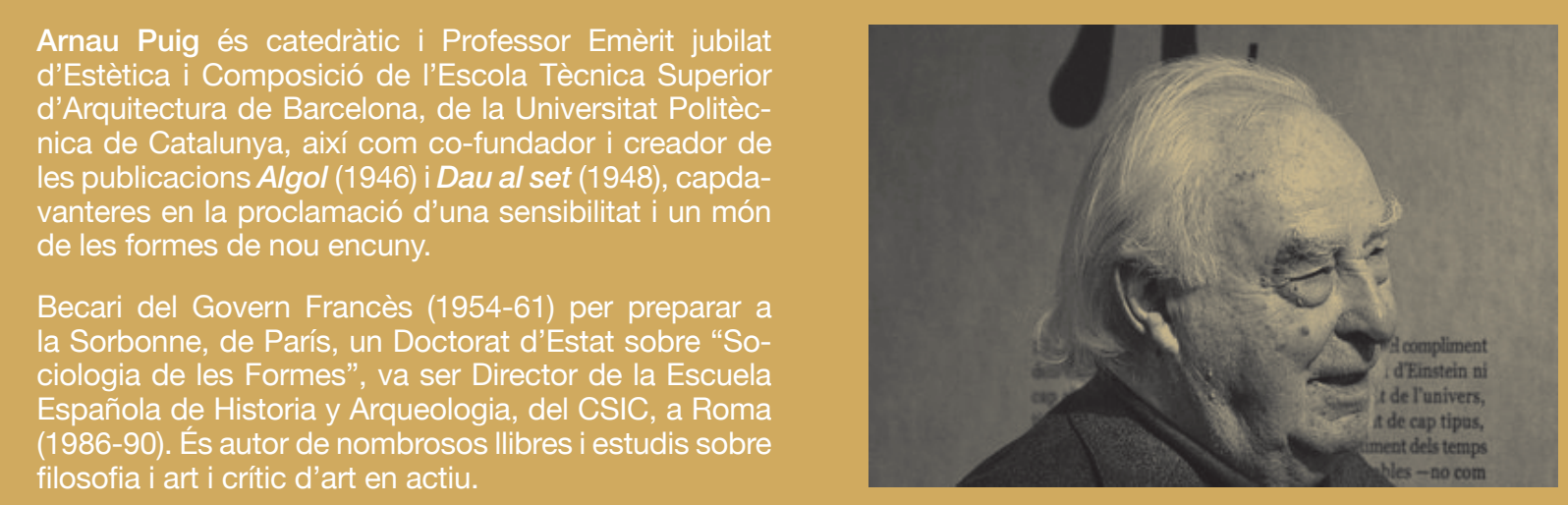

inc ben present que alguns dels membres dels tribunals que presidien les convocatòries a plaça de p. n. n., o de professor ordinari a les que em vaig presentar (en recordo un de "tribunal" amb set membres; cinc, tanmateix, era el més freqüent), alguns d'aquells docents, professionals tots ells, eren personalitats singulars; el mot arquitecte (de argé, principi, responsable primer) els omplia la boca i se sentien, fins un cert punt era filosòficament i moralment lògic - després, obvi, d'haver superat l'arbitrarietat d'un històric i perllongat domini i conformació política per la força -, se sentien creadors de la realitat d'aquest món en el que vivim. L'arquitecte venia a ser l'àrbitre (les formes, l'ambient, l'habitar que genera) de la realitat, sobretot de la nova realitat, aquella en la que treballem, pensem i vivim tots els de més.

Però he de reconèixer que, també, tenien un punt d'humilitat atès que admetien - aquest fou el meu cas - que entre ells hi hagués altres tipus de mentalitat sensible i conceptual. Vaig arribar consolidar per concursos i oposicions successives - a l'Escola de Xavier Rubert de Ventós (ell n'era ja membre i representava, en aquell conclave de professionals de l'arquitectura, un trànsfuga intel'lectual), també gràcies a l'acceptació generosa del purista formalista Josep $\mathrm{M}^{2}$ Sostres $\mathrm{i}$, sempre, amb el beneplàcit dels Solà-Morales, en especial el de l'ínclit Ignasi. A aquell ambient d'arquitectes, orgullosos de l'anomenada i internacionalitat reconeguda de la seva ETSAB, mai m'hi vaig trobar estrany ni forà; sempre vaig ser ben acollit a tots els departaments, fins i tot el de Projectes, el més envanit i prepotent. I era perquè la majoria tenia ben present, com els ho havia preceptuat el mestre historic Vitruvi, que cada arquitecte ha de ser un filòsof $i$, com els ho ha advertit, segles després, Christopher Wren, cada arquitecte s'ha de sentir un cosmòleg expert en llums i ombres. No hi pot haver arquitectura - assajava de definir-los-ho Heidegger - sense un projecte del pensar i del viure, de l'habitar. L'arquitectura, "necessitat racionalitzada per l'enteniment” (Hegel dixit), és la sòlida base de la construcció i arranjament de l'univers. L'arquitectura, afegia Hegel, satisfà no només les necessitats físiques dels humans sinó
també les intencions religioses i politiques. Com funcioni això a la també les intencions religioses i politiques. Com
realitat quotidiana humana, és ja una altra cosa.

Tot plegat treu cap per la intenció amb la que vull tractar aquesta reflexió meva d'ara. He estat temptat - atès que molts ho han fet - de voler parlar d'una possible metafísica a (dic "a" i no "de") l'arquitectura; d'apropar-me al text que l'esmentat filòsof modern va dedicar a l'habitar. Però m'ha resultat impossible; el filòsof alemany ha viscut als limbs d'una mitologia de la realitat que res te a veure amb la realitat sota la que la majoria dels humans, amb treball forçat de cada dia, ha de portar a cap la tasca
poder reposar i aixoplugar-se a un racó.

Es vol fer viure la gent des de l'adquirit, des del llenguatge establert i codificat, com si cada mot - com va dir el poeta J. V. Foix-
fos un maó, un totxo, de la realitat; la gent bé prou tendeix a viure fos un maó, un totxo, de la realitat; la gent bé prou tendeix a viure
des de la pràctica, peró és que els fets no responen als mots que des de la pràctica, però és que els fets no responen als mots que es diu que els representen: el viure, com el discurs, és un construir constant, però a la societat real no encaixen mots i totxos i, generalment, tot plegat és un desori, res és per allò que es diu que serviria. És el que ens ha abocat al que en diem des-construir, que vol dir que, des de la realitat efectiva de cada dia i amb els dia hauríem d'assajar de fer les coses segons més creiem que ens convenen, i no pas com pels mots, les ordres, ens diuen que ho hem de fer. Cada nou dia tot és un dia nou i el passat, si bé és una plataforma, un trampolí per llençar-nos a noves descobertes, no deixa tanmateix de ser un llast, atès que no ens permet enfondir l'esdevenidor com ens seria més plausible, sinó que se'ns obliga a servir-nos del que hi ha, per fer el que no hi ha. I això de cap manera pot respondre a aquella visió constant de descoberta que l'arquitecte, entre els altres humans, té el deure de preparar-nos per a un nou viure en un món que realment cada moment se'n mostra més nou i diferent de tots els que fins ara hem somniat.

La possessió - o domini - de l'espai no n'implica l'habitabilitat. A l'arquitectura hi ha tendència a confondre espai amb funcionalitat vital; però el que és real és que molt sovint qui habita l'espai l'adapta, l'habitar, qui el crea és qui l'habita, el sentit que qui l'ocupa li dóna.
A un moment donat dels dramàtics anys de la postguerra europea i de les migracions vers els centres industrialitzats del món capitalista o el de la utopia del món socialista i/o comunista, se'n va dir - de l'arquitectura als suburbis per enquibir la gent en blocs de mal consolidat formigó, malalt d'antuvi d'aluminosi -, "arquitectura existencial" (des dels anys 60 als noranta, inclosos). Es confonia així el meravellós fet de l'existència amb la feixuga càrrega d'haver-la de viure segons ens indiquessin, o els plagués, a aquells pels quals aquella realitat existencial mancada d'empatia social existia, malgrat parlar-se de socialisme. L'encaixonarment dels humans era un fet vital quotidià. [Un incís que es vol ideològicament esclaridor: un primer existencialisme, l'ideal, el del transcendent i redemptor estar-aquí, era el de Heidegger; el segon, el dels suburbis per encaixonar i tenir a punt la gent per gon, el dels suburbis per encaixonar i tenir a punt
munyir-la cada jornada, era el que definia Sartre.]

La possessió - o domini - de l'espai no n'implica l'babitabilitat. A l'arquitectura bi ba tendència a confondre espai amb funcionalitat vital; però el que és real és que molt sovint qui habita l'espai l'adapta, se l'acomoda als usos dels que en té necessitat. L'espai real, l'babitar, qui el crea és qui l'babita.

Tot això no és fruit de rancors sinó resultat i conseqüències arquitectòniques de pràctiques ben paleses i reconegudes, estudiades i mostrades als llibres i ensenyades com els pròdroms de l'arquitectura funció física i espiritual que es proclama com la de l'esdevenidor i de la que l'esmentat Foix n'era ja un pregonador. Aportarem uns arguments a contrario de tot plegat referint-nos només als exemples adduïts per aquesta reflexiva i raonada publicació (Palimpsesto): els pensats i sentits espais ideals arquitectònics de Rietveld-Shröeder, el Fansworth-Mies van der Rohe i la casa japonesa del te, exemples esclatants d'incoherència entre propòsits mentals i usos emocionals. Els dos primers responen a projectes ideals somniats pels usuaris i l'arquitecte (somnis completament diferenciats per les vivencialitats projectuals i d'ús corresponents - fet psíquic real actiu per mitjà de l'empatia- a cadascun dels interlocutors; o bé la total submissió de l'usuari cadascun dels interlocutors; o be la total submissio de l'usuari de la casa del te als condicionants socials previs exigits a qui ac-
cepta participar a la cerimònia). Hom pot objectar que les realitats responen a factors exògens al fet arquitectònic; cal respondre que responen a factors exògens al fet arquitectònic; cal respondre que no, ates que la fusio inseparable i indestriable era precisament tu pots crear el teu habitar; a no ser que habitar consisteixi en un adaptar-se al que trobes. Això ja ho està fent des de sempre I'home primitiu i el ciutadà que viu a les aglomeracions urbanes modernes.

Després d'informar-nos i llegir atentament aquests relats i experiències del que ha succeilt en uns projectes considerats com exemplars per a l'arquitectura pràcticament actual, em ve a la ment l'experiència viscuda a mitjan anys 80 a Itàlia a propòsit de la, aleshores, nova i recent experiència d'arquitectura dirigida per fer front a les necessitats reals d'habitatge davant de les densificacions humanes urbanes provocades per la industrialització i la conseqüent pressió demogràfica. Es tractava del projecte promogut per l'/stituto autonomo Case Popolare per projecte promogut per I'stituto autonomo Case Popolare per
dotar d'habitació, Bauen diria Heidegger, a la gent, a aquells que dotar d'habitació, Bauen diria Heidegger, a la gent, a aquells que tenen dret natural inalienable, com connotació humana reconeguda per la societat, de
els italians mussolinians).

El projecte, per l'indret on es va construir, era conegut com Nuovo Corviale però per les característiques reals de construcció que presentava, la gent molt aviat va batejar-la com il serpentone (era una construcció de més d'un quilòmetre de longitud, nou plantes d'alçada i amb una capacitat calculada de més de 8.000 habitants). Tot hi era previst: espais comuns, espais privats, espais per i tot el que les ments organitzadores pensaven o poguessin pensar que era necessari pels que l'habitarien. En front del complex per preveure i garantir el que fos o hi manqués hi havia, com arquitecte responsable, Mario Fiorentino, assistit, això sempre, d'un equip de professionals preparats i previsors de i per a tot el que fes referència a les necessitats socials inèdites o no pensades d'aquell nou grup social humà.

Doncs bé, malgrat tanta previsibilitat, res funcionava, tothom s'h sentia a disgust, res era utilitzat segons previsió social. La realitat era que cadascú anava a viure allí amb el seu pre-projecte i amb les seves previsibilitats de nou ús, i es trobava que tot $h$ era pre-establert, pre-condicionat. Era un espai que no podies habitar-lo; t'hi havies d'adaptar: havies d'acceptar la vida que t'hi havien fet. Hom pot dir que això és el socialisme; doncs l'ensulsiada física i moral.

Tanmateix, no m'hauria calgut anar tan lluny ni esperar tant de temps per verificar la inadequació entre projecte arquitectònic realitat d'habitació vital real. L'exemple l'havia tingut l'any 1952 a Barcelona mateix i al barri de la Barceloneta amb la Casa de la Marina, pensada i construïda dins del racionalisme més estricte per José Antonio Coderch i Manuel Valls. Tot hi era establert, racionalitzat i controlat perquè una família de pescadors, prevista de 6 membres, pogués enquibir-s'hi en 72 $\mathrm{m}^{2}$, raciona-litzats i equilibrats. Com que l'artista Guinovart hi de les virtuts prèvies del racionalisme. Al cap d'uns mesos que les famílies s'hi havien instal'lat, canviaven l'ordre i la disposició total de tot; prescindien de les propostes d'interiorisme dels arquitectes $\mathrm{i}$ instal.laven on cabessin aquelles butaques Lluís $\mathrm{XV}$ que sempre havien somniat tenir a casa per escarxofar-s'hi en tornar de la feina. Els estatgers disposaven a la seva manera dels metres quadrats assignats; els hàbits i necessitats personals o del collectiu familiar intervenien $i$ arrancaven dels murs el prèviament previst i ordenaven a criteri seu taules, llits i el que fos, convertint aquell espai racionalitzat en territori de libertat, saltant els uns per sobre dels altres, fent-se cadascú, a hores, el raconet dels seus enyors.

En Guinovart i jo estàvem esborronats d'aquella manca de respecte al nou imperi de les sensibilitats. Però cal reconèixer que a l'Occident i àrees de la seva influència hi és ben establert que o s'accepten els protocols (les rituels d'abord) o hom no cap o no pot assistir a la cerimònia. Era, o és, el dilema de les formes de la contemporaneitat. Ens trobem a aquesta brega. Qui ha d'educar a qui?

La prospectiva tecnològica no és només aquella que pensaren els grans creadors innovadors de la modernitat sinó també aquells arquitectes de la pràctica constructiva que en països en desenvolupament accelerat es veuen impulsats, obligats, no només a construir per enquibir la gent en espais habitables sinó també a prevenir i preveure la quantitat de problemes que generen les aglomeracions humanes, i procedir a que gairebé en e mateix espai i, si és possible, el mateix temps, les persones - en
definitiva tots ho som de persones, tant les acomodades com definitiva tots ho som de persones, tant les acomodades com
les que han d'acceptar el que se'ls ofereix i/o llença - puguin fer les que han d'acceptar el que se'ls ofereix i/o llença - puguin fer
front a tots el requisits que la societat els demana i els exigeix de complir per poder viure i/o subsistir als espai d'habitació als de complir per poder viure i/o subsistir als espai d'habitacio als
que el conglomerat urbà s'ha convertit (Paulo Mendes da Rocha n'és un bon i conscienciat representat i executor d'aquesta arn'és un bon i conscienciat representat i executor d'aquesta arquitectura no només d'habitatge sinó també d'usos i exigèn-
cies socials, entre les que hi ha, no ho oblidem, les dedicades a cies socials, entre les
lleures i diversions).

Si l'arquitectura és una gramàtica, el que escau al nou concepte del construir $i$ habitar és crear més i més possibilitats tècniques iformals que permetin que cadascú els disposi - la sintaxi - a la seva manera. La vida, repetim-ho, és una qüestió de dicció personal que cerca
realitzar-se.

Aquestes meves no són reflexions crítiques, atès que cal reconèixer que modularment existencialment s'ha arribat a establir uns estàndards d'habitatge acceptables; però tampoc s'ha d'amaga que l'arquitectura moderna ha servit també per crear ciutadans adaptats a les precises dependències de la productivitat. Tot, obv també, dins d'uns mòduls que fan més o menys viable ordenar la vida de la gent de manera que no s'hagin de sentir excessivament, cal reconèixer-ho, dins de la severa manera d'un Fahrenheit 451 de ciència ficció. Tots reconeixem tanmateix que el projecte vital hauria de ser quelcom absolutament individualitzat: viure hauria de consistir en poder executar el propi poema. Els passos endavant que ens proposem donar, crec, és per facilitar-ne la realització.

Si l'arquitectura és una gramàtica, el que escau al nou concepte del construir i habitar és crear més i més possibilitats tècniques i formals que permetin que cadascú els disposi - la sintaxi - a la seva manera. La vida, repetim-ho, és una qüestió de dicció personal que cerca realitzar-se. Oh ironia!, un ideal de la con-
servadora caseta i hortet (que també ho volien els arquitectes servadora caseta
racionalistes).

Ser arquitecte conscient és arribar a fer formalment possibles uns projectes vitals. Que l'arquitectura és també una qüestió social?, d'empresa i, molt menys, una qüestió metafísica.

DOI: 10.5821/palimpsesto.11.3698 